\title{
Adolescent goals and aspirations in search of psychological well- being: from the perspective of self-determination theory
}

\author{
Eugene Lee Davids, Nicolette Vanessa Roman and Lynn Joy Kerchhoff
}

\begin{abstract}
According to self-determination theory, an individual's goal content and the processes involved in goal setting often represent the status of the individual's mental health and wellbeing. When examining the importance placed on goal setting, an individual's goals and aspirations are often synonymous with mental health and well-being. Aspiring to achieve intrinsic life goals has been associated with greater psychological well-being in literature. This study therefore aimed to establish the relationships between goals and aspirations, mental health behaviour (interpersonal relations, stress management, and spiritual growth), and psychological well-being (measured by positive affect). A sample of 457 secondary school learners in the Overberg Educational District, Western Cape, South Africa, participated in the study. The results suggest a significant positive relationship between placing importance on intrinsic goals and aspirations, and psychological well-being (as indicated by positive affect). However, psychological well-being was not correlated with mental health behaviour. The results of the hierarchical regression analysis suggest that importance placed on intrinsic goals and aspirations predicts psychological well-being and accounts for $8 \%$ of the variance. The results highlight the role of intrinsic goals and aspirations in predicting the psychological well-being of adolescents. The findings are supported by the theoretical assumptions of self-determination theory.
\end{abstract}

Self-determination theory (SDT) is a theory of human motivation and development (Deci \& Ryan, 2008). The basic assumption is that individuals are capable of motivating themselves to their fullest potential and to work towards a cohesive sense of self (Deci \& Ryan, 2004) as a result of the fulfilment or satisfaction of their basic psychological needs (Haivas, Hofmans, \& Pepermans, 2012). SDT operates on the assumption that the psychological needs are innate and universal (Deci \& Ryan, 2000; Jaakkola, Liukkonen, Laakso, \& Ommundsen, 2008; Milyavskaya et al., 2009). These needs are competence, autonomy, and relatedness (Deci \& Ryan, 2000). Satisfaction of the needs for competence, autonomy, and relatedness is said to envisage psychological well-being (Deci \& Ryan, 2000, 2008; Deci, Vallerand, Pelletier, \& Ryan, 1991; Grouzet et al., 2005; Ingrid, Majda, \& Dubravka, 2009). The goals and aspirations that individuals have often represent the status of their basic psychological needs (Deci \& Ryan, 2000). 
When the basic psychological needs of individuals are satisfied, their goals and aspirations are intrinsic in nature. Intrinsic goals are thought to be associated with behaviours and actions that can be considered as being 'self-determined' (McHoskey, 1999). The intrinsic life goals include aspirations towards personal growth, community contributions, and meaningful relationships (Ingrid et al., 2009; McHoskey, 1999; Williams, Cox, Hedberg, \& Deci, 2000). Conversely, frustration of the basic psychological needs encourages the development of extrinsic life goals, which include wealth, fame, and image (Ryan, Huta, \& Deci, 2008). Intrinsic life goals are largely linked to the three basic psychological needs that promote health and well-being (Niemiec, Ryan, \& Deci, 2009; Vansteenkiste, Matos, Lens, \& Soenens, 2007), while extrinsic life goals limit the chances of becoming involved in basic need-satisfying behaviour; this ultimately leads to a diminished sense of well-being (Vansteenkiste et al., 2004). Behaviours that are experienced as being externally controlled are considered as being extrinsic in nature (McHoskey, 1999). They are also associated with negative associations of self-actualisation, vitality, and positive affect (Williams et al., 2000), which could be a reflection of psychological well-being.

Psychological well-being is concerned with how individuals evaluate fulfilment in their lives across the domains of home life, school, managing situations, and encounters with people (Cripps \& Zyromski, 2009). This perspective is similar to the early work of Ryff and Keyes (1995) which provides a multi-dimensional perspective of psychological well-being. These multi-dimensional aspects include purpose in life, personal growth, positive relations with others, environmental mastery, self-acceptance, and autonomy. Research suggests that psychological well-being is related to positive affect (Urry et al., 2004), which is defined as responding pleasurably to the environment including enthusiasm and alertness (Watson \& Clark, 1984). Affect, whether positive or negative in nature, is common to the daily engagement with life and is central to the well-being which is experienced because the emotional process and cognitive assessment of the mood promote the experiences of psychological well-being (Mitchell, Eby, \& Lorys, 2014). In a study conducted by Garcia et al. (2012), both psychological well-being (indicated as a resource) and positive affect were found to predict regular exercise, less smoking, improved sleeping, and fewer psychosomatic symptoms. The findings were similar across age and gender. However, there is research which suggests that during adolescence, the presence of psychological distress is associated with negative thoughts and emotions, and diminishes psychological health and well-being (Cripps \& Zyromski, 2009).

In the context of SDT, engagement in particular activities and exuding particular behaviours are associated with being intrinsically or extrinsically motivated (Hagger \& Malmberg, 2011; Neyrinck, Vansteenkiste, Lens, Duriez, \& Hutsebaut, 2006). For example, when one considers an activity to be inherently pleasurable, appealing, gratifying, or interesting, this is when an activity is intrinsically motivated. An additional factor is that the involvement in the activity should be for sheer enjoyment with the absence of external forces for involvement in the activity (Neyrinck et al., 2006). Extrinsic motivation would be engagement in an activity for reasons other than pure involvement in the activity but rather to obtain a desired outcome (Neyrinck et al., 2006). Thus, the actions and behaviours 
that humans become involved in and execute are seen as being intentional, goal-oriented, and self-regulatory. The goals, therefore, that adolescents aspire towards and the engagement in behaviours that assist in attaining these goals are related to the level of psychological well-being experienced (Deci \& Ryan, 2000).

\section{The current study}

Adolescence is a developmental phase that is typically considered as being one where psychological well-being is under threat, as the World Health Organization (2012) proposes that $20 \%$ of adolescents experience mental health problems in any given year. This may place strain on the psychological well-being of adolescents. It has become an important public health concern to understand the role of aspirations regarding certain goals and the behaviours associated with psychological well-being of adolescents. The mental health of children and adolescents is important, bearing in mind that the likelihood of maintaining mental health into adulthood is great (Belfer, 2008; Patel, Flisher, Hetrick, \& McGorry, 2007; Pound \& Campbell, 2015). Currently, limited research exists which examines adolescent choice of health behaviour, particularly mental health behaviour such as stress management, interpersonal relations, and spiritual growth (Rew, Arheart, Horner, Thompson, \& Johnson, 2015). The actions and behaviours that aim to promote a lifestyle that constitutes good health and overall well-being are considered to be healthy lifestyle behaviours (Leddy, 2003) and determinants of health status (Lee \& Loke, 2011), including mental health. Wang, Ou, Chen, and Duan (2009) believe that these healthy lifestyle behaviours are important, especially for the health habits employed early in an individual's life. For adolescents in particular, mental health behaviours which they engage in may be a predictor of psychological well-being (Lee \& Loke, 2011). However, as previously indicated, the research on positive adolescent mental health behaviour and well-being is limited. An SDT perspective may assist in understanding the role of goals and aspirations in creating motivation to engage in these mental health activities and behaviours. The research in South Africa on goals and aspirations is limited to and focuses on the context of the family and education (Davids \& Roman, 2013; Roman et al., 2015). This study therefore may be the first in South Africa to provide information on the relationship between goals and aspirations, and mental health behaviour (stress management, interpersonal relations, and spiritual growth) in the prediction of psychological well-being of adolescents. In addition, Kieling and colleagues (2011) allude to the 10\%-90\% split in mental health research of adolescents; the split refers to the location of most mental health research, with $10 \%$ of children and adolescents living in high-income countries, while the remaining 90\% of children and adolescents come from low- to middle-income countries with limited research available examining mental health and the promotion of positive mental health. This study therefore contributes to narrowing the $10 \%-90 \%$ split.

\section{Method}

\section{Participants}

A cross-sectional design was employed to establish whether goals and aspirations and engaging in behaviours that promote positive mental health predict psychological well-being among Grade 9 learners. Grade 9 learners were selected as they are at an important stage in 
their secondary education careers where they need to select main subject areas which are aligned with their aspirations for careers and studies beyond secondary education. In obtaining a heterogeneous group of participants, schools in the Overberg Educational District were stratified by means of socio-economic status (using school fees as an indication). The Overberg Educational District was selected as it is predominately a rural area, and research examining the well-being of adolescents often excludes rural communities and focuses largely on urban samples. Six public schools were randomly selected, two in each strata:

(1) no school fees, (2) school fees between R1and R10oo per annum, and (3) school fees above R10oo per annum. Gaining access to schools where the school fees were above R10oo per annum proved difficult and these schools refused participation in the study; however, four schools that fell within the strata for (1) no school fees and (2) school fees between Riand R100o per annum partook in the study. The sample was made up of 457 Grade 9 learners, with a mean age of 16.31 years (standard deviation $[\mathrm{SD}]=0.45)$, of whom $209(46.2 \%)$ were male and $243(53.8 \%)$ female. Most participants identified as Coloured $(n=248,56.4 \%)$, followed by Black African $(n=186,42.3 \%)$ and White $(n=6,1.4 \%)$. The sample had Afrikaans $(n=253$, $56.5 \%)$ as the most prevalently spoken language; this was followed by isiXhosa $(n=166$, 37.1\%) and English $(n=3,0.7 \%)$. The sample also had 26 (5.8\%) participants who spoke languages which were grouped as 'other'.

\section{Instrument}

The data were collected by means of a self-report questionnaire made up of four sections, namely, (1) a demographic details section, (2) the Aspirations Index (Kasser \& Ryan, 1996), (3) Positive and Negative Affect Schedule (Watson, Clark, \& Tellegen, 1988), and (4) Health-Promoting Lifestyle Profile II Questionnaire (Walker \& Hill-Polerecky, 1996). The Aspirations Index assessed the participants' goals and aspirations by categorising them into intrinsic and extrinsic goals. Intrinsic goals and aspirations are often associated with being psychologically well and are made up of the life goals of personal growth, relationship, and community, while the opposite is assumed for extrinsic goals which are made up of the goals of wealth, fame, and image. The Positive and Negative Affect Schedule assessed the mood of participants, focusing specifically on positive and negative affect. The Health-Promoting Lifestyle Profile II assessed the frequency of engagement in healthy lifestyle behaviours. For this study, the subscales for stress management, interpersonal relations, and spiritual growth were merged to form the variable 'mental health behaviour'. Cronbach's alpha scores in this study were as follows: the Aspirations Index was $\alpha=.80$, the Positive and Negative Affect Schedule was $\alpha=.65$, and the Health-Promoting Lifestyle Profile II Questionnaire was $\alpha=.85$.

\section{Procedure}

Permission was sought from the Western Cape Education Department to access schools in the Overberg Education District. When permission was granted, school principals were invited to partake in the study. The principals and teachers were informed about the study, and a date and time was arranged to explain the study's purpose to the learners at a time that did not disrupt the normal running of the school. Learners were provided with information 
sheets and consent forms to be completed by their parents. Learners who received parental consent were allowed to partake in the study, and they individually assented to participation in the study. The questionnaires were self-administered in a classroom setting where the main researcher was present to assist with any questions that might arise. It was conducted on a date and time which suited the school community, and it took approximately $35 \mathrm{~min}$ to complete.

\section{Ethical considerations}

The University of the Western Cape's research ethics committee granted permission for the research to be conducted. The participants' parents completed consent forms, while the participants completed assent forms before participation in the study. Participation was voluntary, and all information remained anonymous and confidential. Both participants and their parents were informed that the information gathered would be disseminated to assist in knowledge generation. The ethical principles which guided this research study were focused on (1) informed consent and assent, (2) voluntary participation, (3) confidentiality, (4) ensuring that no harm was caused to the participants in the study, and (5) the sampling, data collection, and analysis process was fair and equitable.

\section{Data analysis}

The data were analysed using the Statistical Package for Social Sciences (SPSS), Version 23. Two separate hierarchical multiple regression analyses were conducted: one hierarchical regression analysis was for positive affect and another for negative affect. In an initial assessment of multi-collinearity which can be identified if the correlation matrix suggests high correlations among predictor variables (above .80) according to Field (2013), it was found that this was not the case in the study results (presented in Table 2). Further analysis for multi-collinearity was conducted using the variance inflation factor (VIF) and tolerance statistic for intrinsic goals ( VIF $=1.24$; tolerance $=.81$ ), extrinsic goals $(\mathrm{VIF}=1.24$; tolerance $=.81$ ), and mental health behaviour (VIF $=1.02$; tolerance $=.98$ ). The VIF suggested no bias in the regression as the rule determines that only mean VIF scores substantially greater than 1 suggest that the regression is biased. In addition, when assessing the homogeneity of variance using Levene's test for intrinsic goals $(F(29,271)=1.25, p=.18)$, extrinsic goals $(F(27,238)=3.02, p=.00)$, and mental health behaviour $(F(29,271)=2.02, p=.00)$, the assumption of homogeneity was only violated by extrinsic goals and mental health.

\section{Results}

Table 1 presents the main study variables, as well as the subscales, which were assessed. In Table 1, intrinsic goals $(M=3.13 ; S D=0.43)$ were slightly higher than extrinsic goals $(M=2.95$; $S D=0.43$ ) for the total sample, and this was similar for both male and female adolescents. The most prevalent intrinsic goal was having a sense of community for the total sample $(M=2.99$; $S D=1.19)$, while the most prevalent extrinsic goal was the aspiration of wealth $(M=2.78 ; S D=$ $0.73)$. This was similar for males and females. The aspirations of relationships $(M=2.89 ; S D=$ 1.24) and image $(M=2.72 ; S D=0.75)$ for the total sample were the least prevalent subscales. For males, image was the least prevalent extrinsic goal $(M=2.74 ; S D=0.90)$, while fame was the least prevalent among females $(M=2.68 ; S D=0.67)$. The results presented in Table 2 
suggest that positive affect was significantly correlated with intrinsic goals $(r=.16 ; p<.01)$, while negative affect was correlated with positive affect $(r=.43 ; p<.01)$.

\section{Positive affect}

In Step 1, using hierarchical regression analysis, intrinsic goals $(\beta=.27 ; p=.00)$ significantly and positively predicted positive affect. In Step 2, when adding mental health behaviour, intrinsic goals still remained the only significant and positive predictor of positive affect. The final model explained $8 \%$ of the variance presented for positive affect (Table 3).

\section{Negative affect}

In terms of psychological well-being, positive affect was more prevalent $(M=3.33 ; S D=.65)$ than negative affect $(M=2.46 ; S D=.75)$. Furthermore, participants indicated that they often engaged in behaviours that promote positive mental health and well-being $(M=2.43 ; S D=$ 1.05).

Table I. Variable mean scores.

\begin{tabular}{|c|c|c|c|}
\hline \multirow[t]{2}{*}{ Variable } & \multirow{2}{*}{$\begin{array}{l}\text { Total } \\
\text { sample }\end{array}$} & \multicolumn{2}{|l|}{ Gender } \\
\hline & & Male & Female \\
\hline Intrinsic goals ${ }^{\mathrm{a}}$ & $2.94(1.07)$ & $2.91(1.12)$ & $2.99(1.00)$ \\
\hline Personal growth & $2.92(1.13)$ & $2.89(1.22)$ & $2.98(1.00)$ \\
\hline Relationships & $2.89(1.24)$ & $2.88(1.26)$ & $2.95(1.20)$ \\
\hline Sense of community & $2.99(1.19)$ & $2.96(1.28)$ & $3.06(1.08)$ \\
\hline Extrinsic goals ${ }^{\mathrm{a}}$ & $2.75(0.57)$ & $2.81(0.59)$ & $2.70(0.55)$ \\
\hline Wealth & $2.78(0.73)$ & $2.84(0.73)$ & $2.73(0.74)$ \\
\hline Fame & $2.74(0.67)$ & $2.81(0.66)$ & $2.68(0.67)$ \\
\hline Image & $2.72(0.75)$ & $2.74(0.90)$ & $2.70(0.62)$ \\
\hline Psychological well-beingb & - & - & - \\
\hline Positive affect & $3.33(0.65)$ & $3.33(0.63)$ & $3.33(0.66)$ \\
\hline Negative affect & $2.46(0.75)$ & $2.30(0.70)$ & $2.59(0.76)$ \\
\hline Mental health behaviourc & $2.43(1.05)$ & $2.38(1.12)$ & $2.47(.99)$ \\
\hline Stress management & $2.35(1.06)$ & $2.33(1.10)$ & $2.37(1.02)$ \\
\hline Interpersonal relations & $2.40(1.11)$ & $2.35(1.19)$ & $2.45(1.03)$ \\
\hline Spiritual growth & $2.52(1.17)$ & $2.45(1.25)$ & $2.59(1.09)$ \\
\hline
\end{tabular}

aParticipants responded on a 4-point Likert Scale: I=not very important and 4=very important.

tParticipants responded on a 5-point Likert Scale: I=very slightly and 5=extremely.

cParticipants responded on a 4-point Likert Scale: I=never and 4=always. 
Table 2. Variable correlations.

\begin{tabular}{lllll}
\hline & $\mathrm{I}$ & 2 & 3 & 4 \\
\hline I. Intrinsic goals & - & & & \\
2. Extrinsic goals & $.72^{\text {*** }}$ & - & - & \\
3. Positive affect & $.16^{* *}$ & .10 & $.43^{* *}$ & - \\
4. Negative affect & .04 & -.04 & .04 & .05 \\
5. Mental health behaviour & .10 & .08 & & \\
\hline
\end{tabular}

$* * 0.01$

In terms of mental health behaviour, the most prevalent mental health behaviour was spiritual growth $(M=2.52 ; S D=1.17)$, while the least prevalent behaviour engaged is related to stress management $(M=2.35 ; S D=1.06)$. This was similar for male and female participants. When testing to establish whether there were any significant differences across genders for the main study variables, tests of the five a priori hypotheses were conducted using Bonferroniadjusted alpha levels of .01 per test $(.05 / 5)$. The results suggested that there were no significant main effects across genders for intrinsic goals $(F(1,450)=0.70, p=.40)$, extrinsic goals $(F(1,393)=3.60, p=.06)$, mental health behaviour $(F(1,450)=0.90, p=.34)$, and positive affect $(F(1,298)=0.00, p=.95)$, except for negative affect $(F(1,303)=11.36, p=.00)$. Gender differences were significant for negative affect.

In Step 1, using hierarchical regression analysis, both intrinsic and extrinsic goals were not significant predictors for negative affect. In Step 2, when adding mental health behaviour, there still remained no significant predictors for negative affect (Table 3). 
Table 3. Hierarchical regression analyses (positive and negative affect).

\begin{tabular}{|c|c|c|c|c|}
\hline & $b$ & $\mathrm{SE} \cdot b$ & $\beta$ & $t$ \\
\hline \multicolumn{5}{|l|}{ Positive affect } \\
\hline \multicolumn{5}{|l|}{ Step I } \\
\hline Constant & 2.19 & & & \\
\hline Intrinsic goals & .32 & .08 & $.27^{*}$ & 4.13 \\
\hline Extrinsic goals & .03 & .07 & .03 & .42 \\
\hline \multicolumn{5}{|l|}{ Step 2} \\
\hline Constant & 2.17 & & & \\
\hline Intrinsic goals & .32 & .08 & $.27^{*}$ & 4.13 \\
\hline Extrinsic goals & .03 & .07 & .03 & .39 \\
\hline Mental health behaviour & .01 & .04 & .01 & .19 \\
\hline \multirow{2}{*}{\multicolumn{5}{|c|}{$\begin{array}{l}\text { In Step I: Positive affect: } \Delta R^{2}=.08 \\
\text { In Step 2: Positive affect: } \Delta R^{2}=.08\end{array}$}} \\
\hline & & & & \\
\hline \multicolumn{5}{|l|}{ Negative affect } \\
\hline \multicolumn{5}{|l|}{ Step I } \\
\hline Constant & 2.60 & & & \\
\hline Intrinsic goals & .05 & .10 & .03 & -1.21 \\
\hline Extrinsic goals & -.11 & .09 & -.08 & .49 \\
\hline \multicolumn{5}{|l|}{ Step 2} \\
\hline Constant & 2.58 & & & \\
\hline Intrinsic goals & .05 & .10 & .03 & .47 \\
\hline Extrinsic goals & -.11 & .09 & -.09 & -1.22 \\
\hline Mental health behaviour & .01 & .05 & .01 & .18 \\
\hline \multicolumn{5}{|l|}{ In Step I: Negative affect: $\Delta R^{2}=.0$ I } \\
\hline In Step 2: Negative affect: $\Delta R^{2}=.0$ I & & & & \\
\hline
\end{tabular}

SE: standard error.

${ }^{*} p<0.05$

\section{Discussion}

The aim of the study was to establish whether aspiring to certain life goals and aspirations and engaging in behaviours that promote positive mental health would predict psychological well-being as indicated by positive affect.

In this study, the results indicate that adolescents aspired to both intrinsic and extrinsic goals; however, there was a slightly higher aspiration towards intrinsic goals, in particular the intrinsic life goal of a sense of community. These findings differ from a previous study examining life goals and aspirations of adolescents in South Africa. The results of the previous study found that adolescents aspired to extrinsic life goals, which is common for adolescents and particularly for adolescents from less affluent countries like South Africa (Davids \& Roman, 2013; Grouzet et al., 2005; Ingrid et al., 2009). According to Ingrid et al. (2009), it is not necessarily whether an individual aspires to intrinsic goals that is associated with an individual's well-being, but rather the reasons for aspiring to certain goals that form the $w h y$ and what of aspirations (Koestner, 2008). 
An additional explanation for the results could be that South African communities are more collectivist than individualist, which could explain the prevalence of a sense of community. However, the fact that adolescents had reasons to aspire to extrinsic goals, as presented in the Davids and Roman (2013) study, highlights the contradictory findings on this topic for South African adolescents when compared to this study and internationally (Vansteenkiste, Simons, Lens, Soenens, \& Matos, 2005). Although the results of this study provide information regarding the types of motivation of adolescents, the research is limited and therefore the findings are inconclusive for adolescents in South Africa.

Another aspect of the inconclusiveness of these findings is that they suggest that there is a positive association between intrinsic and extrinsic life goals and aspirations for adolescents. For many, finding an association between life goals and aspirations (associated with positive developmental outcomes), on one hand, and the contrary, on the other, would create confusion. However, Ingrid et al. (2009) have suggested that it is not necessarily the goal type which brings about well-being, but rather why the goal is aspired to. In low- to middleincome countries, one would need to aspire towards life goals that assist in first satisfying the basic instinctual needs. For example, one would not aspire to have a good relationship with someone else when there is no money available to purchase bread to satisfy the hunger that an individual is experiencing. Therefore, in an emerging economy like South Africa where poverty is high, the association could be an indication of how adolescents aspire to both intrinsic and extrinsic goals, and that as one is satisfied, so is the other. So, while an individual might satisfy the extrinsic goal of wealth in order to purchase bread to satisfy hunger, when that goal is satisfied, only then could the individual focus on intrinsic goals related to having a sense of community, personal development, and growth, as well as good relationships. Kasser, Ryan, Couchman, and Sheldon (2004) have also shed light on whether it could be that the goals and aspirations are materialistic - which creates the diminished sense of well-being - and for many developing countries, the goals of wealth are associated with satisfying the basic instinctual needs of hunger, warmth, and shelter. If one had to make use of Maslow's hierarchy of needs, it would also suggest that the basic needs for food and oxygen are the first to be satisfied, before one can become concerned with being selfactualised. This could be similar to understanding the associations between positive and negative affect, when examining health and well-being.

In terms of mental health behaviour, the participants were measured according to stress management, interpersonal relations, and spiritual growth. The results of this study suggest that spiritual growth was more prevalent for adolescents. Petros, Airhihenbuwa, Simbayi, Ramlagan, and Brown (2006) have also reported that religion plays an important role in the lives of South African communities, and this could be associated with the finding that spiritual growth was more prevalent. However, these researchers also mention that religion and religious institutions allow for a perceived safe space for South Africans - and this could promote well-being.

In response to the question whether psychological well-being is a predictive outcome of intrinsic goals and aspirations and mental health behaviour, it was found to be predictive 
for intrinsic goals and aspirations, but not for mental health behaviour. According to SDT, the goals that individuals have tend to direct the activities as well as the behaviours that they are involved in (Deci \& Ryan, 2008). Goals are often seen as being the internal representations of desired outcomes' (Ingrid et al., 2009). Often, extrinsic life goals are associated with negative associations of self-actualisation and diminished positive affect (Williams et al., 2000). Intrinsic life goals and aspirations are often believed to be associated with positive mental health and well-being (Duriez, 2011; Niemiec et al., 2009; Vansteenkiste et al., 2007).

In addition to the results presented, it is noted that the only significant differences which existed between male and female participants was with regard to negative affect. This is interesting, as previous studies have noted gender differences in terms of mood and psychological well-being (Audrain-McGovern, Rodriguez, \& Leventhal, 2014). The differences in relation to affect and psychological well-being have been documented by Fujita, Diener, and Sandvik (1991) who reported a more prevalent negative affect among female participants; however, females experienced similar well-being to male participants. These differences could be accounted for by puberty and the associated physical changes.

The results also highlight the different perspectives of both intrinsic and extrinsic goals and aspirations of adolescents in predicting the psychological well-being of adolescents. Perhaps future studies could examine which other factors may be playing a role in determining why adolescents aspire to certain life goals and aspirations and why psychological well-being is promoted in various aspirations in life. It could mean that achieving intrinsic goals brings about a sense of fulfilment of the goals that were set and could be an explanation for the associations with positive affect (psychological well-being); however, there are also South African studies which have found the opposite of this study.

Methodologically, one of the limitations of the study is that Cronbach's alpha score obtained for the Positive and Negative Affect Schedule was not as high as expected. A limitation therefore arose in the instrumentation, particularly the Positive and Negative Affect Schedule, for a country as diverse and different as South Africa. It would therefore be recommended that future research adapt the schedule for the South African population. Positive affect as measured in the schedule was used as an indicator for psychological wellbeing in the study. Using only this measure (positive affect) to indicate psychological wellbeing can be considered as a limitation. It is therefore recommended that future studies include additional measures that examine more dimensions of psychological well-being. Another limitation is that the results presented were collected in a rural setting in South Africa and may not be representative of findings in urban settings. It would therefore be recommended that future research consider the studied variables within an urban setting to establish whether the findings are similar or different for adolescents in urban settings. In addition, as the assumption of homogeneity was violated for both extrinsic goals and mental health, the results cannot be generalised to the study population. 


\section{Implications for practitioners}

For practitioners who work with adolescents and adults, SDT is an evidence-based theory that could enhance current assessment and intervention strategies. Assessing whether an individual's psychological needs - autonomy, or the need to be in control of one's own behaviour and goals, competence, or the need to be able to master the challenging tasks of one's life and relatedness, or the need to feel a sense of belonging - are being met could foster healthy psychological well-being and increase intrinsic motivation. For lecturers and teachers, understanding and applying the distinction between intrinsic and extrinsic motivation together with students achieving academic goals could lead to changes in how students are supported. This study sheds light on a particular age group of young people who, in the South African context, are about to make significant choices about the subjects that they will select to allow them to enter a career or study path. If students' choices can be informed by an understanding of themselves and their motivation, then this could potentially alleviate some of the stress related to these difficult choices. The relationship between these areas of function and attaining goals and aspirations could easily be explained to adolescents and adults. Once an individual understands this link, practical tips can be suggested for the client to adopt in day-to-day activities. This study questions why there are different findings between adolescent samples with regard to intrinsic motivation. Exploring individual difference and environmental influences on an adolescent's development is key to practitioners - especially within the South African context. Studies that provide clues and insight and which can inform practice will enhance the ability of practitioners to develop targeted intervention strategies to assist the client and society as a whole. For example, during career assessment/counselling, in addition to the traditional techniques used, practitioners can assess whether a client's psychological needs are satisfied or frustrated, as this may provide a link to their psychological well-being. Furthermore, psycho-education for teachers can assist them in understanding how intrinsic motivation evolves and works and they can tailor the way in which they support student's goals.

\section{Conclusion}

SDT operates on the assumption that aspiring to intrinsic life goals is associated with positive psychological health and well-being. This study supports the proposed assumption of SDT regarding intrinsic goals being a positive predictor of psychological well-being. However, other South African studies have found contrary findings for psychological well-being among adolescents, which leaves room for future research to examine the role of goals and aspirations in the promotion of psychological well-being in different cultures.

\section{Funding}

The authors would like to acknowledge the financial support of the National Research Foundation (NRF) South Africa for the research presented in this article. 


\section{References}

Audrain-McGovern, J., Rodriguez, D., \& Leventhal, A. M. (2014). Gender differences in the relationship between affect and adolescent smoking uptake. Addiction, 11O, 519-529.

Belfer, M. L. (2008). Child and adolescent mental disorders: The magnitude of the problem across the globe. Journal of Child Psychology and Psychiatry, 49, 226-236.

Cripps, K., \& Zyromski, B. (2009). Adolescents' psychological well-being and perceived parental involvement: Implications for parental involvement in middle schools. Research in Middle Level Education Online, 33(4), 1-13.

Davids, E. L., \& Roman, N. V. (2013). Does family structure matter? Comparing the life goals and aspirations of learners in secondary schools. South African Journal of Education, $33(3), 1-12$.

Deci, E. L., \& Ryan, R. M. (2000). The 'what' and 'why' of goal pursuits: Human needs and the self-determination of behaviour. Psychological Inquiry, 11, 227-268.

Deci, E. L., \& Ryan, R. M. (2004). Handbook of self-determination research. New York: University of Rochester Press.

Deci, E. L., \& Ryan, R. M. (2008). Self-determination theory: A macrotheory of human motivation, development, and health. Canadian Psychology, 49, 182-185.

Deci, E. L., Vallerand, R. J., Pelletier, L. G., \& Ryan, R. M. (1991). Motivation and education: The self-determination perspective. Educational Psychologist, 26, 325346.

Duriez, B. (2011). The social costs of extrinsic relative to intrinsic goal pursuits revisited: The moderating role of general causality orientation. Personality and Individual Differences, 50, 684-687.

Field, A. (2013). Discovering statistics using IBM SPSS statistics (4th ed.). London, UK: SAGE.

Fujita, F., Diener, E., \& Sandvik, E. (1991). Gender differences in negative affect and wellbeing: The case for emotional intensity. Journal of Personality and Social Psychology, 61, 427-434.

Garcia, D., Archer, T., Moradi, S., \& Andersson-Arntén, A. (2012). Exercise frequency, high activation positive affect, and psychological well-being: Beyond age, gender, and occupation. Psychology, 3(4), 328-336.

Grouzet, F. M. E., Kasser, T., Ahuvia, A., Dols, J. M. F., Kim, Y., Lau, S., . . Sheldon, K. M. (2005). The structure of goal contents across 15 cultures. Journal of Personality and Social Psychology, 89, 800-816.

Hagger, H., \& Malmberg, L. (2011). Pre-service teachers' goals and future-time extension, concerns, and well-being. Teaching and Teacher Education, 27, 598-608.

Haivas, S., Hofmans, J., \& Pepermans, R. (2012). Self-determination theory as a framework for exploring the impact of the organizational context on volunteer motivation: A study of Romanian volunteers. Nonprofit and Voluntary Sector Quarterly, 41, 11951214.

Ingrid, B., Majda, R., \& Dubravka, M. (2009). Life goals and well-being: Are extrinsic aspirations always detrimental to well-being? Psychological Topics, 18, 317-334.

Jaakkola, T., Liukkonen, J., Laakso, T., \& Ommundsen, Y. (2008). The relationship between situational and contextual self-determined motivation and physical activity intensity 
as measured by heart rates during ninth grade students' physical education classes. European Physical Education Review, 14, 13-31.

Kasser, T., \& Ryan, R. M. (1996). Further examining the American dream: Differential correlates of intrinsic and extrinsic goals. Personality and Social Psychology Bulletin, 22, 280-287.

Kasser, T., Ryan, R. M., Couchman, C. E., \& Sheldon, K. M. (2004). Materialistic values: Their causes and consequences. In T. Kasser \& A. D. Kanner (Eds.), Psychology and consumer culture: The struggle for a good life in a materialistic world (pp. 11-28). Washington, DC: American Psychological Association.

Kieling, C., Baker-Henningham, H., Belfer, M., Conti, G., Ertem, I., Omigbodun, O., . . . Rahman, A. (2011).

Child and adolescent mental health worldwide: Evidence for action. The Lancet, 378, 15151525. Koestner, R. (2008). Reaching one's personal goals: A motivational perspective focused on autonomy. Canadian Psychology, 49, 60-67.

Leddy, S.K. (2003). Integrative Health Promotion: Conceptual bases for Nursing Practice. Thorofare, NJ: Slack Inc.

Lee, R.L.T., \& Loke, A.Y. (2011). Lifestyle behaviours and psychosocial well-being of Chinese adolescents in Hong Kong and Guangzhou, China: A cross-sectional comparative survey. Journal of Clinical Nursing, 20(19), 2733-2743.

McHoskey, J. W. (1999). Machiavellianism, intrinsic versus extrinsic goals, and social interest: A self-determination theory analysis. Motivation and Emotion, 23, 267-283.

Milyavskaya, M., Gingras, I., Mageau, G. A., Koestner, R., Gagnon, H., Fang, J., \& Boiché, J. (2009). Balance across contexts: Importance of balanced need satisfaction across various life domains. Personality and Social Psychology Bulletin, 35, 1031-1045.

Mitchell, M. E., Eby, L. T., \& Lorys, A. (2014). Feeling work at home: A transactional model of women and men's negative affective spillover from work to family. In M. J. Mills (Ed.), Gender and the work-family experience (pp. 121-140). Cham, Switzerland: Springer.

Neyrinck, B., Vansteenkiste, M., Lens, W., Duriez, B., \& Hutsebaut, D. (2006). Cognitive, affective and behavioral correlates of internalization of regulations for religious activities. Motivation and Emotion, 30, 323-334.

Niemiec, C. P., Ryan, R. M., \& Deci, E. L. (2009). The path taken: Consequences of attaining intrinsic and extrinsic aspirations in post-college life. Journal of Research in Personality, 43, 291-306.

Patel, V., Flisher, A. J., Hetrick, S., \& McGorry, P. (2007). Mental health of young people: A global public- health challenge. The Lancet, 369, 1302-1313.

Petros, G., Airhihenbuwa, C. O., Simbayi, L., Ramlagan, S., \& Brown, B. (2006). HIV/AIDS and 'othering' in South Africa: The blame goes on. Culture, Health and Sexuality, 8, 67-77.

Pound, P., \& Campbell, R. (2015). Locating and applying sociological theories of risk-taking to develop public health interventions for adolescents. Health Sociology Review, 24(1), 64-80. 
Rew, L., Arheart, K.L., Horner, S.D., Thompson, S., \& Johnson, K.E. (2015). Gender and ethnic differences in health-promoting behaviours of rural adolescents. The Journal of School Nursing, 31(3), 219-232.

Roman, N. V., Davids, E. L., Moyo, A., Schilder, L., Lacante, M., \& Lens, W. (2015). Parenting styles and psychological needs influences on adolescent life goals and aspirations in a South African setting. Journal of Psychology in Africa, 25, 305-312.

Ryan, R. M., Huta, V., \& Deci, E. L. (2008). Living well: A self-determination theory perspective on eudaimonia. Journal of Happiness Studies, 9, 139-170.

Ryff, C.D., \& Keyes, C.L.M. (1995). The structure of psychological well-being revisited. Journal of Personality and Social Psychology, 69(4), 719-727.

Urry, H.L., Nitschke, J.B., Dolski, I., Jackson, D.C., Dalton, K.M., Mueller, C.J., Rosenkranz, M.A., Ryff, C.D., Singer, B.H., \& Davidson, R.J. (2004). Making life worth living: Neural correlates of well-being. Psychological Science, 15, 367-372.

Vansteenkiste, M., Matos, L., Lens, W., \& Soenens, B. (2007). Understanding the impact of intrinsic versus extrinsic goal framing on exercise performance: The conflicting role of task and ego involvement. Psychology of Sport and Exercise, 8, 771-794.

Vansteenkiste, M., Simons, J., Lens, W., Soenens, B., \& Matos, L. (2005). Examining the motivational impact of intrinsic versus extrinsic goal framing and autonomysupportive versus internally controlling communication styles on early adolescents' academic achievement. Child Development, 76, 483-501.

Vansteenkiste, M., Simons, J., Lens, W., Soenens, B., Matos, L., \& Lacante, M. (2004). Less is sometimes more: Goal content matters. Journal of Educational Psychology, 96, $755-764$.

Walker, S. N., \& Hill-Polerecky, D. M. (1996). Psychometric evaluation of the HealthPromoting Lifestyle Profile II. Unpublished manuscript, University of Nebraska Medical Center, Omaha.

Wang, D., Chun-Quan, O., Mei-Yen, C., \& Duan, N. (2009). Health-promoting lifestyles of university students in Mainland China. BMC Public Health, 9, 1-9.

Watson, D., \& Clark, L.A. (1984). Negative affectivity: The disposition to experience aversive emotional states. Psychological Bulletin, 96(3), 465-490.

Watson, D., Clark, L. A., \& Tellegen, A. (1988). Development and validation of brief measures of positive and negative affect: The PANAS scales. Journal of Personality and Social Psychology, 54, 1063-1070.

Williams, G. C., Cox, E. M., Hedberg, V. A., \& Deci, E. L. (2000). Extrinsic life goals and health-risk behaviors in adolescents. Journal of Applied Social Psychology, 30, 17561771 .

World Health Organization. (2012). Adolescent mental health: Mapping actions of nongovernmental organisations and other international development organisations. Geneva, Switzerland: Author. 